\title{
QUEEN'S
UNIVERSITY
BELFAST
}

\section{Multiple traumatisation and subsequent psychopathology in people with intellectual disabilities and DSM-5 PTSD a preliminary study}

Mason-Roberts, S., Bradley, A., Karatzias, T., Brown, M., Paterson, D., Walley, R., Truesdale, M., Taggart, L., \& Sirisena, C. (2018). Multiple traumatisation and subsequent psychopathology in people with intellectual disabilities and DSM-5 PTSD a preliminary study. Journal of Intellectual Disability Research, 62(8), 730-736. https://doi.org/10.1111/jir.12505

Published in:

Journal of Intellectual Disability Research

Document Version:

Peer reviewed version

Queen's University Belfast - Research Portal:

Link to publication record in Queen's University Belfast Research Portal

Publisher rights

Copyright 2018 Wiley. This work is made available online in accordance with the publisher's policies. Please refer to any applicable terms of use of the publisher.

\section{General rights}

Copyright for the publications made accessible via the Queen's University Belfast Research Portal is retained by the author(s) and / or other copyright owners and it is a condition of accessing these publications that users recognise and abide by the legal requirements associated with these rights.

Take down policy

The Research Portal is Queen's institutional repository that provides access to Queen's research output. Every effort has been made to ensure that content in the Research Portal does not infringe any person's rights, or applicable UK laws. If you discover content in the Research Portal that you believe breaches copyright or violates any law, please contact openaccess@qub.ac.uk. 
Multiple traumatization and risk of harm in people with intellectual disabilities and DSM-5

PTSD: A preliminary study

\section{Brief Title}

Trauma and risk of harm

Authors
Susan Mason-Roberts, MSc ${ }^{1}$
Thanos Karatzias, PhD ${ }^{1,2, \mathrm{a}}$
Michael Brown, PhD
Douglas Paterson, MRCPsych
Ro ${ }^{4}$
Robert Walley, D.Psychol 1,3
Maria Truesdale, PhD ${ }^{1}$
Laurence Taggart, PhD $^{6}$
Chammy Sirisena, MRCPsych

\section{$\underline{\text { Affiliations }}$}

${ }^{1}$ School of Health and Social Care, Edinburgh Napier University, Edinburgh, UK

${ }^{2}$ Rivers Centre for Traumatic Stress, NHS Lothian, Edinburgh, UK

${ }^{3}$ Specialist Learning Disability Services, NHS Lothian, Edinburgh, UK

${ }^{4}$ Learning Disability Service NHS Ayrshire \& Arran, UK

${ }^{5}$ Learning Disability Service NHS Lanarkshire, UK

${ }^{6}$ Institute of Nursing and Health Research, University of Ulster, Coleraine, UK

${ }^{7}$ Learning Disability Service NHS Borders, UK

a Address for Correspondence:

Prof. Thanos Karatzias

Edinburgh Napier University

Sighthill Campus

Sighthill Court

Edinburgh EH11 4BN

Scotland UK

Tel. (+44) (0) 1314555345

Email.t.karatzias@napier.ac.uk 


\title{
$\underline{\text { Title }}$
}

Multiple traumatization and risk of harm in people with intellectual disabilities and DSM-5

PTSD: A preliminary study

\begin{abstract}
$\underline{\text { Abstract }}$
Background: It is recognised internationally that individuals with intellectual disability (ID) are at greater risk of being exposed to traumatic events compared to the non-disabled population. Yet no study to date has examined the role of multiple traumatisation and subsequent mental health symptomology in people with ID. The aim of this study was to explore the association between multiple traumatisation and subsequent mental health.

Method: A preliminary quantitative study involving 33 participants with DSM-V PTSD completed self-report questionnaires on exposure to traumatic life events and PTSD symptoms, anxiety, depression and general distress.

Results: A proportion of 55\% of the sample reported exposure to life events in both childhood and adulthood. Those who reported exposure to life events in childhood and adulthood reported significantly higher risk of harm compared to those who reported exposure to life events only in adulthood. The two groups did not differ significantly on measures of PTSD, anxiety, depression and general distress.

Conclusions: Preliminary results indicate that exposure to multiple traumatisation is associated with the risk of harm in people with intellectual disabilities. Clinical implications and directions for future research are discussed.
\end{abstract}

Key words: intellectual disabilities; learning disabilities; developmental disabilities; posttraumatic stress disorder; PTSD; EMDR; trauma 


\section{Introduction}

Individuals with intellectual disabilities (ID) have an increased risk of exposure to traumatic life events such as long-term physical, interpersonal, and sexual abuse (Pestka \& Wendt, 2014; Byrne, 2017). Exposure to traumatic events in this population group has been associated with numerous mental health conditions (for review see Hulbert-Williams \& Hastings, 2008) including; anxiety (e.g. Bonell- Pascual, Huline-Dickens, Hollins 1999), Post Traumatic Stress Disorder (PTSD) (e.g. Mevissen \& de Jongh, 2010; Wigham \& Emerson, 2015), and symptoms of depression and aggressive or self-injurious behaviour (e.g. Esbensen, \& Benson, 2006; Peckham, Corbett, Howlett, McKee \& Pattison, 2007; Jowett, Karatzias, Brown, Grieve, Paterson et al., 2016). Compared to the non-disabled population, people with ID are more like to develop traumatic stress following exposure to traumatic events (Hatton \& Emerson 2004; Focht-New et al., 2008). This might be due to a number of reasons including difficulties in recognising and avoiding potentially dangerous situations (Focht-New et al., 2008), a reduced ability to process traumatic memories (Breslau, et al., 2006) or lack of social support, and communication difficulties (Tomasulo \& Razza, 2007).

Although individuals with ID are at greater risk of being exposed to multiple traumatic events, particularly in childhood, (McCarthy, 2007; Emerson, 2013, Hatton \& Emerson 2004), and are more vulnerable to developing severe mental health problems following trauma (e.g. Wigham \& Emerson, 2015), there have been few studies that have examined the experience of negative life events and effect on mental health in people with ID. Research in this area has predominantly focused on single life events, for example, sexual abuse (Sequeira and Hollins, 2003; Byrne, 2017) and bereavement (MacHale \& Carey, 2002). However, some studies have explored the association between a range of life events and subsequent psychopathology in adults with ID (Hastings, Hatton, Taylor, \& Maddison, 2004; Owen et al., 2004; Hamilton, Sutherland, \& Iacono, 2005; Esbensen \& Benson, 2006). Nevertheless, these studies relied on 
informants such as carers and family members to provide information and none of these studies assessed lifetime history of traumatic life events and severity of DSM-V PTSD, anxiety, and depression in a single study. We aimed to preliminary address these gaps in the literature.

\section{Methods}

\section{Design and Participants}

Participants in this study were recruited from a trial on psychological therapies for PTSD. Participants were adults with ID who were attending one of 6 NHS outpatient clinics in the UK for this population and they have had history of at least one traumatic life event. Fiftyone participants who met inclusion criteria were identified and approached to take-part; of those, 33 individuals consented (65\%) and agreed to participate.

Participants were included if they had an ID, were over 18 years old, and were able to give informed consent. All potential participants identified by clinicians completed the PostTraumatic Stress Disorder Checklist (PCL-5; Weathers et al., 2013). Individuals unwilling to participate, who did not give consent or who attended psychotherapy services in the voluntary or private sector were excluded from the study. Ethical approval was obtained from the appropriate Ethics Committee within the UK.

\section{Measures}

\section{Traumatic events}

The Life Events Checklist (LEC; Gray, Litz, Hsu, \& Lombardo, 2004) is a 17-item, selfreport measure that screens for potentially traumatic events in the respondent's lifetime and was used to assess adulthood trauma. The measure demonstrates good test-retest reliability and convergent validity (Gray et al., 2004). 
The Childhood Trauma Questionnaire (CTQ; Bernstien \& Fink, 1998) is a 28-item selfreport questionnaire that assesses history of childhood emotional, sexual and physical abuse and emotional and physical neglect The measure demonstrates good internal consistency, testretest reliability, and convergent validity (Bernstein \& Fink, 1998).

\section{PTSD}

The Post-Traumatic Stress Disorder Checklist (PCL-5; Weathers, et al., 2013) is a 20item self-report questionnaire, which assesses DSM-5 posttraumatic symptoms. The measure has good reliability and validity across a range of populations (e.g. Bovin, Marx, Weathers, Gallagher, Rodriguez et al., 2016).

\section{Anxiety}

The Glasgow Anxiety Scale for People with a Learning Disability Scale (GAD-LD; Mindham \& Espie, 2003) is a 27-item self-report scale that comprises the 'three systems' of cognitive, behavioural and somatic symptoms which co-present anxiety disorders. The measure has demonstrated good test retest reliability and validity in adults with an ID (Mindham \& Espie, 2003).

\section{Depression}

The Glasgow Depression Scale for People with a Learning Disability Scale (GD-LD; Cuthill Espie \& Cooper, 2003) is a 20 item self-report scale to measure depression symptoms in individuals with ID. The measure has demonstrated good test retest reliability and validity in adults with an ID (Cuthill et al., 2003). 


\section{Psychological wellbeing}

Clinical Outcomes in Routine Evaluation - Learning Disability (CORE - LD; Marshall \& Willoughby-Both, 2007) is a 34-item generic measure of psychological distress comprising of 4 domains: functioning (6 items), problems (10 items), well-being (3 items), and risk (5 items). The measure has shown good test retest reliability and validity in adults with an ID (Marshall \& Willoughby-Both, 2007; Brooks, Davies \& Twigg, 2013).

\section{Statistical analysis}

Two groups were created; one with participants who reported traumatic life events only in adulthood $(\mathrm{N}=15)$ and another with participants who reported traumatic life events in both childhood and adulthood $(\mathrm{N}=18)$. Data was analysed using SPSS (version 20). Comparisons between groups were made by means of $t$ tests for parametric data and Mann-Whitney $U$ test for comparisons where assumptions of normality were not met (Field, 2009).

\section{Results}

\section{Sample characteristics}

The mean age of participants was $41(\mathrm{Sd}=11.9)$. There were $20(39 \%)$ males and 13 (61\%) females. The majority had attended primary/secondary education $(66.7 \%)$, were taking psychotropic medication at the time of assessment (75.8\%), and had a diagnosis of mild ID (72.7\%). Just over half of participants had another co-morbid condition (57.6\%) (Table 1).

[Table 1 about here] 


\section{Nature of life events in childhood and adulthood}

All participants reported having experienced at least one traumatic life events (Table 1). Over half of the participants $(n=18,55 \%)$ reported that they had experienced traumatic events in both childhood and in adulthood, and just under half of the sample reported only experiencing trauma during adulthood $(n=15,45 \%)$. No participants reported exposure to traumatic events in only in childhood. Of those who experienced childhood trauma (Table 2), the most common event reported was physical abuse (67\%) and $42 \%$ were exposed to more than one type of trauma.

The most common life event reported in adulthood (Table 3) was physical assault (64\%). Nearly all participants (97\%) reported experiencing more than one type of traumatic event in adulthood. The mean number of life events experienced was $4.6(\mathrm{Sd}=1.97)$

[Table 2 about here]

[Table 3 about here]

\section{Childhood and adulthood trauma in ID}

The childhood and adulthood trauma group scored higher on the measures of functioning (CORE), PTSD (PCL) and depression (GDS), however, was almost equal or lower in anxiety scores for the child and adulthood trauma group compared to the adulthood only group (Table 4). This difference only reached significance on the CORE subscale of Risk, $t$ ($2.580)=3.44, p<.05, d=23.98$ (see Table 4). There were not significant differences between males and females.

\section{Discussion}

In this first ever preliminary study, it was found that a proportion of $55 \%$ of the sample reported exposure to life events in childhood and adulthood. Those who reported exposure to 
traumatic life events in childhood and adulthood reported significantly higher risk of harm to self and others compared to those who reported exposure to life events only in adulthood.

The finding regarding the association between multiple traumatisation and risk of harm to oneself and others support findings from previous studies in people with ID (e.g. O'Callaghan, 2003; Peckham, et al., 2007). However, and considering evidence from the nondisabled population (e.g. Briere, Kaltman, \& Green, 2008; Cloitre, Cohen, Edelman, \& Han, 2001; Yates, 2004; Cloitre, Stolbach, Herman, van der Kolk , Pynoos, et al., 2009; Rytwinski, Scur, Feeny, \& Youngstrom, 2013), it was surprising that multiple traumatisation was not found to be associated with increased PTSD, depressive and anxiety symptomatology. Although this might reflect a unique profile of the traumatic symptomatology in people with ID (McCarthy, 2007; Byrne, 2017), our results require replication with larger samples.

Another limitation of the present study is that the PCL-5 scale is not standardised in people with ID and there has been concern raised that the concept of PTSD, and its effect on mental health for the non-disabled population, may be limited when applied to people with ID (Byrne, 2017). There is a need for further work on the phenomenology and standardisation of instruments that correspond to conditions of traumatic stress as per DSM-V and the forthcoming ICD-11. The ICD-11 will include a new condition of traumatic stress, Complex PTSD (CPTSD), which is associated with multiple traumatisation (Karatzias, Shevlin, Fyvie, Hyland, Efthymiadou et al., 2017) and new instruments for the assessment of CPTSD (Karatzias, T. Shevlin, T Fyvie, C Hyland, Efthymiadou et al., 2016) have emerged in the literature.

\section{Conclusion}

On the basis of these findings we recommend routine screening of traumatic life events and subsequent distress in people with ID. 
Table 1: Demographic Characteristics $(n=33)$

\begin{tabular}{llc}
\hline Factor & Level/Units & Mean (SD) or $n(\%)$ \\
\hline Age $(\mathrm{n}=31)$ & & $41(11.9)$ \\
Gender & Male & $20(39)$ \\
Living arrangements & Female & $13(61)$ \\
& Alone & $6(18.18)$ \\
& With others & $11(33.33)$ \\
& Hospital & $1(3.03)$ \\
Education & Supported living & $11(33.33)$ \\
& Unknown & $4(12.12)$ \\
Medication & Basic & $22(66.67)$ \\
& Higher & $7(21.21)$ \\
ID & Unknown & $4(12.12)$ \\
& Yes & $25(75.76)$ \\
& No & $4(12.12)$ \\
Co-morbidity & Unknown & $4(12.12)$ \\
& Mild & $24(72.73)$ \\
& Moderate & $5(15)$ \\
Trauma & Unknown & $4(12)$ \\
& Yes & $19(57.58)$ \\
& No & $10(30.30)$ \\
& Unknown & $4(12.12)$ \\
& Childhood only & $0(0)$ \\
& Adulthood only & $15(45.45)$ \\
& Childhood and adulthood & $18(54.55)$ \\
\hline
\end{tabular}

Table 2: Childhood trauma $(n=18)$

\begin{tabular}{lc}
\hline Childhood trauma & $\mathrm{n}(\%)$ \\
\hline Emotional Abuse & $9(50.0)$ \\
Emotional Neglect & $9(50.0)$ \\
Physical Abuse & $12(66.7)$
\end{tabular}


Table 3: Adulthood trauma $(n=33)$

\begin{tabular}{lc}
\hline Adulthood trauma & $\mathrm{n}(\%)$ \\
\hline Natural disaster & $1(3)$ \\
Fire & $6(18.2)$ \\
Vehicle accident & $7(21.2)$ \\
Serious accident & $10(30.3)$ \\
Toxic substance & $6(18.2)$ \\
Physical assault & $21(63.6)$ \\
Weapon assault & $9(27.3)$ \\
Sexual assault & $16(48.5)$ \\
Other sexual & $12(36.4)$ \\
Captivity & $10(30.3)$ \\
Illness & $13(39.4)$ \\
Extreme suffering & $1(3)$ \\
Witnessed death & $1(3)$ \\
Death of relative & $22(66.7)$ \\
Caused injury/death & $3(21.2)$ \\
\hline
\end{tabular}

Table 4: Trauma group differences in psychological wellbeing, PTSD symptomology, anxiety and depression $(\mathrm{N}=33)$ 


\begin{tabular}{|c|c|c|c|c|c|c|}
\hline & $\begin{array}{c}\text { Measures of } \\
\text { psychopathology }\end{array}$ & $\begin{array}{c}\text { Overall } \\
\text { Mean (Sd) }\end{array}$ & $\begin{array}{c}\text { Adulthood } \\
\text { only } \\
(n=15) \\
\text { Mean or } \\
\text { median (Sd) }\end{array}$ & $\begin{array}{l}\text { Childhood \& } \\
\text { Adulthood } \\
(n=18) \\
\text { Mean or } \\
\text { median (Sd) }\end{array}$ & $\begin{array}{l}\text { t or Mann- } \\
\text { Whitney u }\end{array}$ & Sig. \\
\hline \multicolumn{7}{|l|}{ CORE } \\
\hline & Functioning & $4.70(2.47)$ & $3.80(2.21)$ & $5.44(2.48)$ & -1.99 & .055 \\
\hline & Problems ${ }^{a}$ & $11.5(3.92)$ & $11.00(2.80)$ & $13.00(4.55)$ & 176.0 & .145 \\
\hline & Risk & $1.79(1.83)$ & $1.00(.93)$ & $2.44(2.15)$ & -2.58 & $.016^{*}$ \\
\hline & Social $^{\mathrm{a}}$ & $6.45(2.24)$ & $7.00(1.92)$ & $7.50(2.52)$ & 136.5 & .957 \\
\hline & Wellbeing & $3.30(1.29)$ & $3.20(1.27)$ & $3.39(1.34)$ & -.41 & .681 \\
\hline & Total & $27.76(9.28)$ & $25.0(5.39)$ & $30.06(11.22)$ & -1.60 & .103 \\
\hline \multicolumn{7}{|l|}{ PCL } \\
\hline & Arousal & $12.88(4.93)$ & $12.73(4.68)$ & $13.00(5.26)$ & -.15 & .880 \\
\hline & Avoidance $^{\mathrm{a}}$ & $4.91(1.57)$ & $4.00(1.92)$ & $5.00(2.20)$ & 169.5 & .215 \\
\hline & Alterations & $15.42(6.14)$ & $14.27(7.03)$ & $16.39(5.32)$ & -.99 & .331 \\
\hline & Re-experiencing & $13.42(4.38)$ & $13.27(4.35)$ & $13.56(4.53)$ & -.19 & .845 \\
\hline & Total & $\begin{array}{c}46.64 \\
(12.57)\end{array}$ & $44.87(13.49)$ & $48.11(11.95)$ & -.73 & .469 \\
\hline \multicolumn{7}{|l|}{ GAS } \\
\hline & Behavioural/specific & $7.58(3.58)$ & $7.60(3.52)$ & $7.56(3.52)$ & .04 & .972 \\
\hline & Somatic/physiological & $10.03(3.15)$ & $10.13(2.75)$ & $9.94(3.62)$ & .16 & .867 \\
\hline & Cognitive/worries & $13.30(3.41)$ & $13.13(3.27)$ & $13.44(8.88)$ & -.26 & .978 \\
\hline & Total & $30.91(7.94)$ & $44.87(6.96)$ & $30.94(5.26)$ & -.03 & .880 \\
\hline GDS & & $17.82(6.19)$ & $16.27(3.73)$ & $17.50(7.54)$ & -1.41 & .171 \\
\hline
\end{tabular}

Note: ${ }^{a}$ Median and Mann Whitney U, * significant at .05 level $9^{\text {a }}$

\section{References}

Bernstein, D.P, \& Fink, L. (1998). Childhood Trauma Questionnaire: A retrospective self-report manual San Antonio, TX: The Psychological Corporation. 
Bonell-Pascual, E., Huline-Dickens, S., Hollins, S., et al (1999) Bereavement and grief in adults with learning disabilities. A follow-up study. British Journal of Psychiatry, $175,348-350$.

Bovin, MJ., Marx, BP., Weathers, FW., Gallagher, MW., Rodriguez, P., Schnurr, P., Keane, P. \& Terence, M. (2016) Psychometric properties of the PTSD Checklist for Diagnostic and Statistical Manual of Mental Disorders-fifth edition (PCL-5) in veterans. Psychological Assessment. 28, 1379-1391.

Breslau, N., Lucia,VC., \& Alvarado, GF. (2006) Intelligence and other predisposing factors in exposure to trauma and posttraumatic stress disorder: a follow-up study at age 17 years. Arch Gen Psychiatry. 63(11), 1238-45.

Briere, J., Kaltman, S., \& Green, B. L. (2008). Accumulated childhood trauma and symptom complexity. Journal of Traumatic Stress, 21, 223-226.

Byrne, G. (2017) Prevalence and psychological sequelae of sexual abuse among individuals with an intellectual disability: A review of the recent literature, Journal of Intellectual Disabilities, 1-17

Cloitre, M., Cohen, L. R., Edelman, R. E., \& Han, H. (2001). Posttraumatic stress disorder and extent of trauma exposure as correlates of medical problems and perceived health among women with childhood abuse. Women and Health, 34, 1-17. 
Cloitre, M., Stolbach, C., Herman, J., van der Kolk , B., Pynoos, R., Wang, J. \& Petkova. E. (2009) A Developmental Approach to Complex PTSD: Childhood and Adult Cumulative Trauma as Predictors of Symptom Complexity, Journal of Traumatic Stress, 22 (5), 399-408

Cuthill, FM., Espie, CA. \& Cooper, SA. (2003) Development and psychometric properties of the Glasgow Depression Scale for people with a Learning Disability. The British Journal of Psychiatry, 182 (4), 347-353; DOI: 10.1192/bjp.182.4.347

Esbensen, A. J., \& Benson, B. A. (2006). A prospective analysis of life events, problem behaviors and depression in adults with intellectual disability. Journal of Intellectual Disability Research, 50, 248-258.

Emerson, E. (2013) Commentary: childhood exposure to environmental adversity and the well-being of people with intellectual disabilities. Journal of Intellectual Disability Research, 57(7), 589-600 doi: 10.1111/j.1365-2788.2012.01577.x

Field, A. P. (2009). Discovering statistics using SPSS. London, England : SAGE

Focht-New G., Clements, P. T., Barol, B., Faulkner M. J., \& Pekala, K. (2008). Persons With Developmental Disabilities Exposed to Interpersonal Violence and Crime: Strategies and Guidance for Assessment. Perspectives in Psychiatric Care, 44, 3-13.

Gray MJ, Litz BT, Hsu JL, Lombardo TW (2004) The psychometric properties of the life events checklist. Assessment 11, 330-341 
Hatton C. \& Emerson E. (2004) The relationship between life events and psychopathology amongst children with intellectual disabilities. Journal of Applied Research in Intellectual Disabilities 17, 109-17

Hollins, S. \& Esterhuyzen, A. (1997) Bereavement and grief in adults with learning disabilities. British Journal of Psychiatry, 170, 497-501.

Hulbert-Williams, L., \& Hastings, R. P. (2008). Life events as a risk factor for psychological problems in individuals with intellectual disabilities: A critical review. Journal of Intellectual Disability Research, 52, 883-895. doi:10.1111/j.1365-2788.2008.01110.x

Jowett, S., Karatzias, T., Brown, M., Grieve, A., Paterson, D. \& Walley, R. (2016) Eye movement desensitization and reprocessing (EMDR) for DSM-5 posttraumatic stress disorder (PTSD) in adults with intellectual disabilities: A case study review. Psychol Trauma, 8(6), 709719, DOI:10.1037/tra0000101

Karatzias T, Shevlin M, Fyvie C, Hyland P, Efthymiadou E, Wilson D, Roberts N, Bisson JI, Brewin CR, Cloitre M (2017) Evidence of distinct profiles of posttraumatic stress disorder (PTSD) and complex posttraumatic stress disorder (CPTSD) based on the new ICD11 Trauma Questionnaire (ICD-TQ). Journal of Affective Disorders, 207, 181-187.

Karatzias T, Shevlin M, Fyvie C, Hyland P, Efthymiadou E, Wilson D, Roberts N, Bisson JI, Brewin CR, Cloitre M (2016) An initial psychometric assessment of an ICD-11 
based measure of PTSD and complex PTSD (ICD-TQ): evidence of construct validity. Journal of Anxiety Disorders 44 , 73-79. 10.1016/j.janxdis.2016.10.009

Marshall, K. \& Willoughby-Booth, S. (2007) Modifying the Clinical Outcomes in Routine Evaluation measure for use with people who have a learning disability. British Journal of Learning Disabilities, 35, 107-112. doi:10.1111/j.1468-3156.2006.00422.x

McCarthy, J (2007) Post-traumatic stress disorder in people with learning disability. Advances psychiatric treatments. 7,163-169

Mevissen, L., \& de Jongh, A. (2010) PTSD and its treatment in people with intellectual disabilities. A review of the literature. Clinical Psychology Review, 30, 308-316.

Mindham, J. \& Espie, CA. (2003) Glasgow Anxiety Scale for people with an Intellectual Disability (GAS-ID): development and psychometric properties of a new measure for use with people with mild intellectual disability. $J$ Intellect Disabil Res., 47(1):22-30. DOI: 10.1046/j.1365-2788.2003.00457.x

O'Callaghan AC, Murphy G \& Clare ICH (2003) The impact of abuse on men and women with severe learning disabilities and their families. British Journal of Learning Disabilities 31: 175-180. DOI: 10. 1111/j.1468-3156.2003.00254.x.

Peckham, N. G., Corbett, A., Howlett, S., McKee, S. \& Pattison, S. (2007) The delivery of a survivors' group for learning disabled women with significant learning disabilities who have been sexually abuse. British Journal of Learning Disabilities, 35, 236-244 
Pestka K \& Wendt S. (2014) Belonging: women living with intellectual disabilities and experiences of domestic violence. Disability \& Society, 29 (7), 1031-1045.

Ryan, R. (1994) Post-traumatic stress disorder in persons with developmental disabilities. Community Mental Health Journal, 30, 45-53

Rytwinski, NK., Scur, MD., Feeny, NC., \& Youngstrom, EA. (2013) The cooccurrence of major depressive disorder among individuals with posttraumatic stress disorder: a meta-analysis. J Trauma Stress. 26(3), 299-309.

Sequeira, H. \& Hollins, S. (2003) Clinical effects of sexual abuse on people with learning disability, British Journal of psychiatry, 182, 13-19

Stavrakaki, C. (1997) Anxiety disorders in persons with mental retardation: diagnostic, clinical and treatment issues. Psychiatric Annals, 27, 182-189.

Tomasulo, D.J. \& Razza, N.J. (2007) Posttraumatic Stress Disorder. In: Fletcher, R., Loschen, E., Stavrakaki, C., \& First, M. (Eds). Diagnostic Manual-Intellectual Disability (DMID): A textbook of diagnosis of mental disorders in persons with intellectual disability (pp. 365-378). Kingston, NY: NADD Press.

Weathers, F.W., Litz, B.T., Keane, T.M., Palmieri, P.A., Marx, B.P. \& Schnurr, P.P. (2013) The PTSD checklist for DSM-5 (PCL-5). National Center for PTSD

Wigham, S. \& Emerson, E. (2015) Trauma and Life Events in Adults with Intellectual Disability, Current Developmental Disorders Reports, 2 (2), 93-99 
Wigham, S., Hatton, C., \& Taylor, J.L. (2011) The Effects of Traumatizing Life Events on People With Intellectual Disabilities: A Systematic Review, Journal of Mental Health Research in Intellectual Disabilities, 4:1, 19-39, DOI:

$10.1080 / 19315864.2010 .534576$ 